\title{
EPIDEMIOLOGICAL DATA ON THE NUTRITIONAL STATUS OF CANCER PATIENTS RECEIVING TREATMENT WITH CONCOMITANT CHEMORADIOTHERAPY, RADIOTHERAPY OR SEQUENTIAL CHEMORADIOTHERAPY TO THE ABDOMINOPELVIC AREA
}

\author{
Aurora Serralde-Zúñiga1§, Denisse Castro-Eguiluz $2 \S$, José luis Aguilar-Ponce ${ }^{3}$, Angélica \\ Andrea Peña-Ruiz ${ }^{3}$, Jorge Víctor Castro-Gutiérrez ${ }^{3}$, Samuel Rivera-Rivera ${ }^{4}$, Carlos Aranda-Flores 5 , \\ Verónica Casique-Pérez ${ }^{3,6}$, Silvia Eugenia Alarcón-Barrios ${ }^{3}$, Jaime de la Garza-Salazar ${ }^{3}$, \\ MiRIAM SÁNCHEZ-LóPEZ ${ }^{3}$ AND Alfonso DueÑas-GonzÁLEZ ${ }^{7 *}$ \\ ${ }^{1}$ Department of Nutrition, Instituto Nacional de Ciencias Médicas y Nutrición Salvador Zubirán, Mexico City; ${ }^{2}$ Consejo \\ Nacional de Ciencia y Tecnología (CONACyT) - Department of Clinical Research, Instituto Nacional de Cancerología, \\ Mexico City; ${ }^{3}$ Departments of Internal Medicine, Nutrition and Clinical Research, Instituto Nacional de Cancerología, \\ Mexico City; ${ }^{4}$ Sociedad Mexicana de Oncología A.C., Mexico City; ${ }^{5}$ Consejo Mexicano de Oncología, A.C., Mexico City; \\ ${ }^{6}$ Department of Nutrition, Facultad de Ciencias de la Salud, Universidad Autónoma de Tlaxcala, Tlaxcala, Tlax., Mexico; \\ ${ }^{7}$ Instituto de Investigaciones Biomédicas UNAM-Instituto Nacional de Cancerología, Mexico City, Mexico.
}

\begin{abstract}
Cancer patients are particularly susceptible to undernourishment so associated weight loss is frequent. Approximately $15 \%$ of patients lose $>10 \%$ of their usual body weight, $40-80 \%$ become undernourished, and about $20 \%$ die as a result. Well-nourished patients have a higher survival rate when compared with patients at risk of undernourishment (19.9 vs. 3.7 months); hence, nutritional intervention is pivotal. Undernourishment negatively influences the patient's prognosis, and its prevalence depends on the tumor type and location, disease stage, treatment, and the applied nutritional evaluation tool. During abdominopelvic radiotherapy, up to $90 \%$ of patients experience symptoms of varying severity; weight loss during radiotherapy is an early indicator of nutritional deterioration, and he the use of radiation is associated with a higher likelihood of undernourishment. In patients with gynecological malignancies, $12.5-54 \%$ are malnourished before receiving oncological treatment, worsening after treatment in $35.8-82 \%$ of cases. There is also deterioration of the nutritional status in patients with colorectal cancer once pelvic radiotherapy is initiated, whereby $50 \%$ of cases are malnourished at the beginning of treatment, and $66.7 \%$ are so when it ends. Although there are notable differences in the impact of radiotherapy on weight according to the radiated region, $88 \%$ patients receiving abdominal radiotherapy were found to lose weight compared to $38 \%$ of patients whose treatment was limited to the pelvis. (REV INVES CLIN. 2018;70:117-20)
\end{abstract}

Key words: Epidemiology. Pelvic cancer. Radiotherapy. Chemotherapy. Nutritional status. Gastrointestinal toxicity.

Corresponding author:

*Alfonso Dueñas-González

Subdirección de Investigación Clínica

Instituto Nacional de Cancerología

Av. San Fernando, No. 22

Col. Sección XVI, Del. Tlalpan

C.P. 14080, Ciudad de México, México

E-mail: alfonso_duenasg@yahoo.com

$\S$ These authors contributed equally to this work.

Received for publication: 02-03-2018

Approved for publication: 03-05-2018

doi:10.24875/RIC.18002523 


\section{INTRODUCTION}

Cancer patients are particularly susceptible to undernourishment and its consequent decrease in the fat and muscle compartments. It results from the adverse effects derived from the tumor or the cancer treatment, be it chemotherapy, radiotherapy, both, or surgery. All cancer treatments may compromise food intake, digestion, and nutrient absorption, hence aggravating the nutritional status of the patient. Undernourishment negatively affects the patient's prognosis as it impacts disease progression, diminishes the response to cancer treatment, worsens the patient's quality of life, increases the hospital stay, and decreases the survival rate. All these factors contribute to an increase in health-care expenses ${ }^{1}$. In these patients, weight loss is frequent whereby approximately $15 \%$ of cancer patients lose $>10 \%$ of their usual body weight ${ }^{2}, 40-80 \%$ become undernourished ${ }^{3}$, and about $20 \%$ die as a result ${ }^{4}$. The prevalence of weight loss depends on the type of tumor and its location, disease stage, treatment, and the applied nutritional evaluation tool. Nutritional intervention is important because well-nourished patients evaluated by the subjective global assessment (SGA) tool, have a higher survival rate when compared with patients at risk of undernourishment or that have some degree of undernourishment (19.9 months in well-nourished patients, SGA A, compared to 3.7 months in patients at risk of undernourishment, SGA B, or patients with undernourishment, SGA C) ${ }^{5}$.

Nutritional conditions classified as malnutrition, overweight, or obesity have different implications, and all carry a bad prognosis in cancer patients. Greater histological aggressiveness has been described in overweight and obese patients with prostate cancer and those with breast cancer. Furthermore, undernourishment has been associated with histological aggressiveness in patients with lung, colorectal, head and neck, stomach and esophagus cancers ${ }^{6}$. A cohort study described the body mass index (BMI) of 404 patients with cervical cancer: malnourished patients (BMl $<18.5 \mathrm{~kg} / \mathrm{m}^{2}$ ) with cervical cancer at stages IB1/IB2 had a decreased overall survival (hazard ratios $=2.37 ; 95 \%$ confidence intervals [Cl], 1.28-4.38; $p<0-01)^{7}$. The 5 -year overall survival rate was $33 \%$ for a $\mathrm{BMl}<18.5 \mathrm{~kg} / \mathrm{m}^{2}, 60 \%$ for a BMl between $18.5 \mathrm{~kg} / \mathrm{m}^{2}$ and $24.9 \mathrm{~kg} / \mathrm{m}^{2}$, and $68 \%$ for a $\mathrm{BMl}>24.9 \mathrm{~kg} / \mathrm{m}^{2}$. A BMl $<18.5 \mathrm{~kg} / \mathrm{m}^{2}$ was associated with an increased risk of Grade 3 or 4 complications when compared with a BMl $>24.9 \mathrm{~kg} / \mathrm{m}^{2}$.

Depletion of muscular mass is more relevant than BMI in the nutritional diagnosis because it is associated with poor function and has an impact on morbidity and mortality, thus decreasing survival ${ }^{6,8,9}$. Bioelectrical impedance analysis is a technique that evaluates changes in body composition and nutritional status. Phase angle measurement, derived from bioelectrical impedance, reflects the relative contribution of fluid and cell membranes from the body whereby a smaller phase angle suggests cell death and a reduction in cellular integrity, and a greater phase angle reflects a higher amount of intact cell membranes. Phase angle measurement is a prognostic marker in diverse diseases and one of the most sensitive markers of undernourishment. In colorectal cancer patients $(n=52)$, a phase angle $>5.57^{\circ}$ was significantly associated with a better survival rate (median survival of 40.4 months), compared to smaller phase angles (median survival of 8.6 months $)^{10}$.

\section{EPIDEMIOLOGICAL DATA}

The type of gynecological tumor has an influence on the nutritional status, increasing the patients' risk of developing malnutrition. In a Korean study, malnutrition was found in $47.9 \%$ of cervical cancer patients, in $52.8 \%$ of ovarian cancer patients, and in $60 \%$ of endometrial cancer cases $^{11}$. Considering the disease stage, $48 \%$ of patients in Stage I, $42.9 \%$ of patients in Stage II, $65 \%$ of patients in Stage III, and $55.6 \%$ of patients in Stage IV were undernourished. Malnutrition was more prevalent in patients who received chemotherapy than in patients not treated with chemotherapy within the previous 6 months. Depression and loss of appetite are significant predictive factors of malnutrition (odds ratio $[O R]=1.087, p=0.01$, and $\mathrm{OR}=0.749, \mathrm{p}=0.002$, respectively) in gynecological cancer patients ${ }^{11}$. Level of evidence $B$.

The tool used to assess nutritional status determines the prevalence of malnutrition. A cross-sectional study that analyzed 66 patients with colorectal cancer demonstrated that when using anthropometric markers, $7.6 \%$ of patients were undernourished according to their BMI, $53 \%$ were undernourished according to the tricipital skinfold, and $36.4 \%$ according 
to the SGA ${ }^{12}$. Therefore, it is advisable to perform a complete nutritional assessment using objective and subjective tools ${ }^{12}$ and to supply documented evidence of the deterioration in the patient's nutritional status with different nutritional assessment tools ${ }^{13}$. Level of evidence B.

Radiotherapy is a cornerstone of cancer treatment. It is applied to the abdominal or pelvic regions for gynecological, urological, and lower gastrointestinal cancer treatment, as a single therapy or in combination with surgery or chemotherapy. It is used to treat thousands of patients every year. During fractionated pelvic radiotherapy, administered daily for 5-7 weeks, up to $90 \%$ of patients experience symptoms of variable severity due to the proximity of the gastrointestinal tract to the pelvic organs. The symptoms experienced during treatment include changes in bowel habits in $94 \%$ of patients, loose stools in $80 \%$, frequency in $74 \%$, difficulty passing gas in $65 \%$, pain in $60 \%$, distress in $48 \%$, tenesmus in $44 \%$, restrictions in daily activity in $40 \%$, urgency in $39 \%$, and fecal incontinence in $37 \%^{14}$. In $5-10 \%$ of patients, serious chronic complications may develop, such as obstruction due to progressive fibrosis, fistulae, and vascular sclerosis $^{15}$. Other less severe bowel symptoms appear in $6-78 \%$ of patients, which, nevertheless, compromise their quality of life. These may include urgency, frequency, fecal incontinence, diarrhea, steatorrhea, tenesmus, pain, constipation, and weight loss. The severity of acute bowel toxicity may predetermine the degree of chronic bowel changes. Therefore, early intervention to prevent or reduce acute toxicity may be worthwhile in the long term ${ }^{15}$. Level of evidence $B$.

Several studies have evaluated the impact of radiotherapy on the patients' nutritional status ${ }^{15,16}$. Previous or current radiotherapy has been significantly associated with undernourishment $(\mathrm{OR}=1.53 ; 95 \%$ Cl 1.21-1.92) ${ }^{16}$. Level of evidence B.

There are important differences in the impact of radiotherapy, depending on the irradiated area. In a study of patients who received abdominal radiotherapy, $88 \%$ experienced important weight loss, losing an average of $3.4 \mathrm{~kg}$, in comparison to patients receiving pelvic radiotherapy, of whom $38 \%$ lost an average of $2.4 \mathrm{~kg}^{17}$; other authors have reported an average weight loss of $4.4 \mathrm{~kg}(p=0.06)^{18}$. Level of evidence B. Furthermore, it has been demonstrated that patients with cervical cancer have vitamin deficiencies, even before they begin cancer treatment. In particular, significantly decreased levels of plasma folate, Vitamin $A$, and Vitamin $C$ have been reported $^{19}$. Level of evidence $B$.

Using several nutritional markers, malnutrition has been documented in women with cervical cancer more frequently than in patients with other gynecological tumors $(p=0.02)^{20}$. According to the patientgenerated SGA, $66 \%$ of cervical cancer patients are either at nutritional risk or malnourished even before receiving cancer treatment ${ }^{21,22}$. Indeed, the prevalence of malnutrition in cervical cancer patients covers a wide range, varying from $4 \%$ in Stage I to $60 \%$ in Stage IV ${ }^{23}$. Weight loss in these patients goes in hand with a low nutrient intake, which has been reflected in altered levels of plasma phospholipids ${ }^{24}$. Other authors have described that $31.6 \%$ of patients with cervical cancer are at severe risk of malnutrition, as assessed by nutritional risk screening ${ }^{25}$. Weight loss is greater in patients receiving radiotherapy $(-3.6$ $\pm 5.6 \mathrm{~kg}$, in relation to the previous 6 months), compared to untreated patients $(+0.2 \pm 2.2 \mathrm{~kg})$, mainly as a result of gastrointestinal symptoms such as constipation, anorexia, nausea, vomiting, and diarrhea25, aside from the decreased caloric and protein intake. Undernourishment is frequently caused by a reduced dietary intake. In 31 rectal cancer patients, dietary intake decreased by $15 \%$ at 5 weeks after radiotherapy, associated to a temporary weight loss of $1 \mathrm{~kg}^{26}$. Another study has described this nutritional decline in patients with colon cancer: when initiating pelvic radiotherapy, $50 \%$ of patients were undernourishment, while $66.7 \%$ were undernourishment by the end of treatment $(p<0.05)^{27}$. The authors did not record a significant reduction in energy and protein intake, but a reduction in serum zinc levels was described $(95.9 \mu \mathrm{g} / \mathrm{dl}-78 \mu \mathrm{g} / \mathrm{dl})^{27}$. Level of evidence B.

Using bioelectrical impedance, abnormalities in the phase angle have been described $\left(-0.23^{\circ} \pm 0.37\right)$ in association with the severe weight loss ( $>5 \%$ of usual weight) observed in $19 \%$ of patients in the month following pelvic radiotherapy $(-1.26 \mathrm{~kg} \pm 2.09 \mathrm{~kg})^{28}$. Moreover, once radiotherapy is concluded, patients may persist with gastrointestinal symptoms (30\%$66 \%$ ) depending on the type of cancer and irradiated area, and patients describe them as detrimental to their quality of life ${ }^{29-31}$. Level of evidence $B$. 


\section{CONCLUSIONS}

Several observational studies have documented the negative impact of oncological treatment on the nutritional status of patients, whether treatment is based on radiotherapy, chemotherapy or both. Unfortunately, due to the heterogeneity of the patients included in these studies, the type of tumor, clinical stage, nutritional assessment, or treatment, it was not always possible to draw conclusive interpretations of the results. Even so, it is clear that cervical cancer patients are at high risk of developing undernourishment, and radiotherapy treatment further increases this condition.

\section{REFERENCES}

1. Huhmann MB, August DA. Review of American society for parenteral and enteral nutrition (ASPEN) clinical guidelines for nutrition support in cancer patients: nutrition screening and assessment. Nutr Clin Pract. 2008;23:182-8.

2. Tisdale M. Mechanisms of cancer cachexia. Physiol Rev. 2009; 89:381-410.

3. Isenring E, Cross G, Daniels L, Kellett E, Koczwara B. Validity of the malnutrition screening tool as an effective predictor of nutritional risk in oncology outpatients receiving chemotherapy. Support Care Cancer. 2006;14:1152-6.

4. Wu BW, Yin T, Cao WX, et al. Clinical application of subjective global assessment in Chinese patients with gastrointestinal cancer. World J Gastroenterol. 2009;15:3542-9.

5. Gupta D, Lis CG, Vashi PG, Lammersfeld CA. Impact of improved nutritional status on survival in ovarian cancer. Support Care Cancer. 2010;18:373-81.

6. Ramos Chaves M, Boléo-Tomé C, Monteiro-Grillo I, Camilo M, Ravasco P. The diversity of nutritional status in cancer: new insights. Oncologist. 2010;15:523-30.

7. Kizer NT, Thaker PH, Gao F, et al. The effects of body mass index on complications and survival outcomes in patients with cervical carcinoma undergoing curative chemoradiation therapy. Cancer. 2011;117:948-56

8. McMillan DC. An inflammation-based prognostic score and its role in the nutrition-based management of patients with cancer. Proc Nutr Soc. 2008;67:257-62.

9. Prado CM, Lieffers JR, McCargar LJ, et al. Prevalence and clinical implications of sarcopenic obesity in patients with solid tumours of the respiratory and gastrointestinal tracts: a populationbased study. Lancet Oncol. 2008;9:629-35.

10. Gupta D, Lammersfeld CA, Burrows JL, et al. Bioelectrical impedance phase angle in clinical practice: implications for prognosis in advanced colorectal cancer. Am J Clin Nutr. 2004;80:1634-8.

11. Nho JH, Kim SR, Kwon YS. Depression and appetite: predictors of malnutrition in gynecologic cancer. Support Care Cancer. 2014;22:3081-8.
12. Barbosa LR, Lacerda-Filho A, Barbosa LC. Immediate preoperative nutritional status of patients with colorectal cancer: a warning. Arq Gastroenterol. 2014;51:331-6.

13. Planas M, Peñalva A, Burgos R, et al. Guidelines for colorectal cancer: effects on nutritional intervention. Clin Nutr. 2007;26:691-7.

14. Khalid U, McGough C, Hackett C, et al. A modified inflammatory bowel disease questionnaire and the Vaizey Incontinence questionnaire are more sensitive measures of acute gastrointestinal toxicity during pelvic radiotherapy than RTOG grading. Int J Radiat Oncol Biol Phys. 2006;64:1432-41.

15. McGough C, Baldwin C, Frost G, Andreyev HJ. Role of nutritional intervention in patients treated with radiotherapy for pelvic malignancy. Br J Cancer. 2004;90:2278-87.

16. Hébuterne X, Lemarié E, Michallet M, Montreuil CB De, Schneider SM. Prevalence of malnutrition and current use of nutrition support in patients with cancer. J Parenter Enter Nutr. 2014;38:196-204.

17. Pezner R, Archambeau J. Critical evaluation of the role of nutritional support with chemotherapy. Cancer. 1985:55:263-7.

18. Chowdhury Q, Elahi F, Olson AK, Khaled MA. Adjuvant nutritional therapy in the management of malnourished cancer patients. Pakistan J Nutr. 2002;1:119-20.

19. Orr JW, Wilson K, Bodiford C, et al. Nutritional status of patients with untreated cervical cancer. II. Vitamin assessment. Am J Obstet Gynecol. 1985;151:632-65

20. Zorlini R, Cairo AA, Gurgel MS. Nutritional status of patients with gynecologic and breast cancer. Nutr Hosp. 2008;23:577-83.

21. Santoso JT, Cannada T, O'Farrel B, Alladi K, Coleman RL. Subjective versus objective nutritional assessment study in women with gynecological cancer: a prospective cohort trial. Int J Gynecol Cancer. 2004;14:220-3.

22. Rodrigues CS, Lacerda MS, Chaves GV. Patient-generated subjective global assessment as a prognosis tool in women with gynecologic cancer. Nutrition. 2015;31:1372-8.

23. Laky B, Janda M, Bauer J, Vavra C, Cleghorn G, Obermair A. Malnutrition among gynaecological cancer patients. Eur J Clin Nutr. 2007;61:642-6

24. Lisboa AQ, Rezende M, Muniz-Junqueira MI, Ito MK. Altered plasma phospholipid fatty acids and nutritional status in patients with uterine cervical cancer. Clin Nutr. 2008;27:371-7.

25. Hertlein L, Kirschenhofer A, Fürst S, et al. Malnutrition and clinical outcome in gynecologic patients. Eur J Obstet Gynecol Reprod Biol. 2014;174:137-40.

26. Guren MG, Tobiassen LB, Trygg KU, Drevon C, Dueland S. Dietary intake and nutritional indicators are transiently compromised during radiotherapy for rectal cancer. Eur J Clin Nutr. 2006:60:113-9.

27. Mahdavi R, Faramarzi E, Mohammad-Zadeh M, Ghaeammaghami J, Jabbari MV. Consequences of radiotherapy on nutritional status, dietary intake, serum zinc and copper levels in patients with gastrointestinal tract and head and neck cancer. Saudi Med J. 2007;28:435-40.

28. Paixao EM, Gonzalez MC. A prospective study on the radiation therapy associated changes in body weight and bioelectrical standardized phase angle. Clin Nutr. 2015;34:496-500.

29. Gami B, Harrington K, Blake P, et al. How patients manage gastrointestinal symptoms after pelvic radiotherapy. Aliment Pharmacol Ther. 2003;18:987-94.

30. Olopade FA, Norman A, Blake P, et al. A modified inflammatory bowel disease questionnaire and the vaizey incontinence questionnaire are simple ways to identify patients with significant gastrointestinal symptoms after pelvic radiotherapy. $\mathrm{Br}$ J Cancer. 2005;92:1663-70.

31. Andreyev $\mathrm{HJ}$, Davidson SE, Gillespie $\mathrm{C}$, Allum WH, Swarbrick E. Practice guidance on the management of acute and chronic gastrointestinal problems arising as a result of treatment for cancer. Gut. 2012;61:179-92. 